\title{
Modern information technologies in the hotel business: development trends and implementation issues
}

\author{
Olga Voronova $^{1, *}$, Viktoria Khareva $^{1}$, and Tatyana Khnykina $^{1}$ \\ ${ }^{1}$ Peter the Great St. Petersburg Polytechnic University, Saint Petersburg, Russian Federation
}

\begin{abstract}
This article discusses the main developments in information technologies of the hotel business, which is especially relevant due to the fact that today the process of economy digitalization in the Russian Federation significantly influences hospitality industry. Automation of hotels associated with the use of modern technologies particularly improves the quality of customer service. In this research major trends in the development of information technologies in hotel business were identified. They include: cloud computing, artificial intelligence, blockchain, augmented reality, etc. This paper defines the main problems of introduction of modern information technologies in hospitality industry. The study revealed that currently, information technologies are improving rapidly, directly impacting hotel business, but also assessing hotel market of the Russian Federation. In terms of development and use of modern information technologies it is important to note that a lot depends on management of a specific hospitality enterprise.
\end{abstract}

\section{Introduction}

Today, the process of digitalization of the Russian economy has a significant impact on hospitality industry. In particular, automation of hotels associated with the use of modern technologies significantly improves the quality of customer service. Digitalization is becoming a major trend, which is evident in the distribution models of hotel services, and also actively comes to the sphere of automation of internal business processes (communication with customers, distribution of tasks within the team, electronic folders and menus, etc.). Both the hotel room capacity and public areas are automated. Today a modern hotel is a place where everything is created exclusively for the convenience and comfort of customers.

\footnotetext{
${ }^{*}$ Corresponding author: ilina.olga@list.ru
} 


\section{Main directions of development of digital innovations in the hotel business}

Digital innovations are gradually becoming the new standard of hotel service. In addition to two obvious trends, which are development of mobile services for guests and launch of services based on gadgets, - digitalization of hotels also includes introduction of advanced solutions for analytics and security. POS systems and hotel digital security systems are responsible for collecting and analyzing various layers of data about visitors. Using this information, hotels can encourage frequent visitors and draw conclusions about customer behavior and preferences, and prepare advanced analytics [1]. Digital security systems can not only track the slightest disturbance of the public peace, but also provide additional information. For example, Marriott hotels have navigation tags that allow to identify frequent visitors (this is implemented via contacting users' smartphones if they have the Marriott app installed). These guests receive information about discounts and special offers.

At present day, it is too early to assess the effectiveness of some recent innovations, that are related mostly to the hotel's image and attract customers. For instance, at the Pengheng Space Capsules Hotel in Shenzhen, China, all the staff at the reception and in the restaurant was replaced by robots. Perhaps the large-scale introduction of such services is not a trend of tomorrow, however, certain patterns of development in hotel business technologies can be traced quite clearly.

\section{Main trends in the development of information technologies in the hotel business}

The main trends in the use of modern technologies in hospitality industry in the conditions of digitalization of the economy are presented in figure 1 . 
Main trends in the application of modern technologies in hospitality industry

\begin{tabular}{|c|}
\hline Use of cloud technologies \\
\hline Artificial intelligence \\
\hline Blockchain \\
\hline SaaS (software as a service) \\
\hline Advertising technologies (digital assistants, nanobloggers, chatbots) \\
\hline Augmented reality technologies \\
\hline Emergence of open software interfaces \\
\hline Analysis of cash transactions \\
\hline Analysis of speech scripts \\
\hline Biometrics and facial recognition \\
\hline Use of voice assistants \\
\hline Outsourcing of information services \\
\hline
\end{tabular}

Fig. 1. Major trends in introduction of modern technologies at the enterprises of hospitality industry.

Let's look at them in more detail.

\subsection{Use of cloud technologies}

Currently, an increasing number of enterprises in hospitality industry prefer these technologies replacing the use of local servers [2]. The main disadvantages of traditional technologies include the following: local server requires regular maintenance from the system administrator; access to database is restricted by local network facilities; connection speed is limited by the speed of a local provider and divided among all who are drawn to the sever database [3]. Using cloud technologies, on the contrary, has a number of advantages: cloud server is maintained by Data center specialists; changing the computing power provided is software-based and does not require physical actions; access to database is limited only by access rights (user name and password); data access speed is limited only by the access speed of a specific user; access continuity, since Data center has several duplicate communication channels and sources of emergency energy saving [4].

\subsection{Artificial intelligence}

As an example of using this technology, we can cite already implemented "smart" rooms (artificial intelligence adjusts the lighting and temperature, and also turns on the client's 
favorite TV shows and provides one with drinks). Also in Japan, the use of robot butlers has been recognized as successful. Artificial intelligence recognizes dozens of languages. In addition, hotels may have devices that track the location of customer's smartphones in order to investigate customer habits and meet their needs at the time of their arrival by generating and issuing appropriate commands to the service staff [5]. Artificial intelligence plays an equally important role in improving the efficiency of public catering enterprises. For example, courier logistics allows to analyze the arrival time of the courier and instructs the kitchen to start cooking dishes to finish them right before the arrival of the courier [6]. Use of artificial intelligence also allows to analyze the work of the restaurant, and to detect violations of rules by the staff via control of bills, number of the discount card uses, as well as the number of cancellations and deletions of checks.

\subsection{Blockchain}

Transactions and transfers of funds when processing an order using Blockchain smart contracts can be performed within a few seconds without the use of a third party, such as a traditional banking system. The issue of privacy that characterizes traditional tourism industry is also addressed through blockchain technology, minimizing exposure to sensitive data in the face of existing problems with cyber attacks and fraud in traditional financial services.

The result is a revolutionary operating system that provides customer satisfaction, integration of big data and the introduction of artificial intelligence into the industry, and high-level data protection to deliver a decentralized transaction on the Blockchain platform.

Integration refers to such services as:

- Letting of houses and exchange of real estate.

- Rent of all available cars.

- Booking excursions, selection of guides.

- The largest list of all attractions, bars and restaurants with decentralized ratings.

- Access to all insurance companies for instant registration of travel policies.

- The largest tourist information portal with all the information required for a traveler.

This technology can be used to accept payment for services using "digital money". Blockchain identification of hotel customers can also be performed [7].

\subsection{SaaS (software as a service)}

When using traditional technologies, licenses are purchased by a one-time payment without limiting their validity period [8]. Purchased licenses cannot be returned or sold to third parties. In the case of purchasing SaaS licenses hospitality industry enterprises get a number of advantages, such as: licenses are paid on a monthly basis, which significantly reduces one-time investment; if the concept of hospitality industry enterprise changes, it is possible to change the composition of paid licenses.

\subsection{Advertising technologies (digital assistants, nanobloggers, chatbots in social networks)}

Almost all companies in hospitality industry have started to think about using chatbots to solve specific business problems [9]. As a rule, this technology is used for automatic answers to frequent customer questions; as the first line of technical support; consultations via WhatsApp on the site; conducting surveys and competitions [10]. 
Currently, advertising is often used by various bloggers, while the hospitality industry enterprises are beginning to call for nanobloggers (bloggers whose number of followers is is not higher than 50 thousand people), rather than "millionaires". This trend is associated with a higher impact on a rather narrow target audience.

\subsection{Augmented reality technologies}

Emergence of new interactive technologies has caused profound changes in the tourism industry and its sectors, offering consumers new experiences and new experiences. One of the ways to get competitive advantages for accommodation facilities is to invest and use new technologies. In this regard, augmented reality is the most promising technology for the modern tourism industry. its development and application can increase the competitiveness of destinations.

Use of augmented reality in the hospitality industry is limited only by the creativity of the accommodation facilities themselves. This technology will help to create a "brand impression" of a hotel visit: it combines the physical parameters of the placement with the intangible aspects of its brand.

Augmented reality can be used to interact with guests before, during, and after their stay. The appeal of the technology encourages users to download the hotel app, allowing the accommodation facility to make a first impression and establish a direct communication channel with its potential guests. During their stay, augmented reality can be used to log in and keep users logged in, thus collecting information to create a more detailed guest profile.

Augmented reality technologies can be used to stimulate travel purchases (the effect of being present in a hotel room, as well as demonstrating the environment and local services using a virtual reality headset). Also, virtual and augmented reality, including those with tactile sensations, can be implemented by digital concierges to issue recommendations to the client on various issues and types of recreation (for example, to provide the client with the opportunity to swim under water with scuba diving using virtual and augmented reality technologies) [11].

\subsection{Emergence of open software products - Application Programming Interface, API}

It can be used to provide integration between various technological systems used in hotels [12]. The API allows one hotel technology system to automatically (i.e., without the participation of hotel employees) interact with another technology system and gain access to its functionality.

Application Programming Interface (application programming interface, application programming interface). The largest companies develop APIs for clients or internal use at some stage.

\subsection{Analysis of cash transactions}

The main objectives of this technology are: analysis of the company's video archive, comparison of personnel actions with the accounting log of operations of the accounting system, analysis of compliance with standards of behavior by personnel, reduction of rules violation.

The cashier receives payments and makes payments to guest accounts, updates information about the client's expenses. The most intensive period of the cashier's work is at the hour of departure of guests. In the cash transactions section, guest accounts are updated, checks are cashed (if such a service is provided), debts are reconciled, daily 
reports are prepared, and payments from customers are accepted. The staff of the cash operations section works with guest files-documents where all charges to the client's account for the current visit are recorded. Special programs are used to process them. Accruals for purchased services are automatically reflected on the customer's account in the computer of the reception and placement service. This helps to avoid paperwork and ensures accuracy of the accounts.

The result of the analysis of cash transactions is a regular analysis and detailing of violations, categorization of violations, development of measures to counter violations, training of personnel [13].

\subsection{Analysis of speech scripts}

With the help of innovative speech analytics technologies in the tourism and hospitality industry, it becomes possible to increase the efficiency of business indicators and improve the quality of service.

The main objectives of this technology are: audio recording of calls, conversations of staff, analysis of compliance by staff with standards of behavior and correct technologies, analysis of identifying the best sales, identifying best practices, reducing service time [14].

With the help of speech Analytics tools, specialists can work with $100 \%$ of requests. To do this, all dialogues are translated into text and analyzed using a special system. Search tools in arrays of unstructured speech information allow an analyst to work out hypotheses (find keywords) on samples of hundreds of thousands of phonograms in a few seconds.

Based on this analysis, you can develop a change program for existing procedures and processes and optimize self-service systems (personal account, website).

Speech analytics tools allow to solve problems that inevitably arise in the hotel business: increasing company revenue by increasing sales efficiency, reducing costs by increasing productivity and reducing redundant contacts, and increasing customer satisfaction with service.

The result of the introduction of innovative speech analytics technologies will be an increase in sales efficiency, an increase in loyalty and customer satisfaction, a reduction in service costs without loss of quality, and behavioral analytics.

\subsection{Biometrics and facial recognition}

Plastic access cards, key rings and passwords have proven their vulnerability - over the years, many cases of theft, forgery and fraud have been recorded. Having entered the security market, biometric technologies have surpassed all these technologies both in providing personal protection and in increasing the effectiveness of identification and verification in various sectors.

Currently, biometrics can already be used to identify and confirm the client's identity. Face scanning technologies when registering with the service. For example, for payment, it may be enough to look at the camera installed on the checkout.

Analysts predict that the international market for biometric solutions for the hotel sector will grow exponentially in the coming years. Biometrics, as the most reliable and accurate authentication system, can provide real-time information about employees and their use of their working time. Using fingerprint readers to track employee attendance can save hotels an average of 2.2 percent of the payroll per year. Biometric time tracking terminals will help you get an idea of how an employee manages their working time, and in accordance with the information received, make adjustments to their pay.

According to forecasts, increased security risks strongly affect the speed of adoption of biometrics in the hotel sector of the economy. The use of biometric identification and 
verification devices will significantly improve the quality of customer service, as well as improve the speed and efficiency of staff work.

The result of using this technology is payment without wallets and Bank cards, increasing the speed of customer service, and a high level of security.

\subsection{Use of voice assistants}

In 2018, Amazon presented a special version of the voice assistant for hotels - Alexa for Hospitality, which is currently being tested in Marriott hotels. To implement the voice assistant, Echo smart speakers are used, which are located in each room. The voice assistant allows the client to get all the necessary information about the hotel, order services from the room, find out information about various facilities (for example, fitness centers, pools near the hotel), and contact the Concierge or reception. You can also configure the voice assistant to control smart equipment: adjusting the air temperature, lighting, raising and lowering the blinds, playing music, and controlling the TV.

At the same time, the use of Echo speakers in hotels raises concerns about the privacy of personal data. Amazon claims that audio recordings of the guest's voice commands will be deleted every day, and the hotel administration will not have access to both request records and response records. If users can connect their voice assistant to an Amazon account and use subscriptions to music services, the connection will be automatically reset when they leave the hotel.

\subsection{Outsourcing of information services}

IT outsourcing is the transfer to a third-party contractor (outsourcer) of all or part of the functions for servicing the organization's information needs.

Currently, this technology is becoming increasingly common in the hospitality industry. Potential clients of outsourcing firms are small businesses that are limited in resources, large companies and banks that have the opportunity to conduct a competition to select the most suitable performers, representative offices of foreign companies and joint ventures that have experience in using outsourcing, however, in other conditions, as well as state organizations that are interested in attracting qualified specialists.

Outsourcing (external source) is the transfer of certain business processes or production functions by an organization to another company that specializes in the relevant field. Unlike services of service and support with a single, episodic, random and bounded beginning and end, outsourcing is usually transferred the function of professional support uninterrupted performance of individual systems and infrastructure based on long contract (minimum 1 year).

The main point of switching to outsourcing is to optimize the company's costs while significantly improving the quality of services provided.

The main criteria for outsourcing are the lack of competitive advantages and not the strategic position of this operation or function for the company

Advantages of this technology include the following: employees are interchangeable, which ensures continuity of services provided; the qualification of employees is usually higher than the average for the market, or that the average employer can afford; only the cost of services is paid, the purchase and updating of programs do not concern the customer; the cost of paying for services is offset by an increase in the expenditure base of the hospitality industry, which reduces income taxes [15]. 


\section{Main problems of introduction of modern information technologies in the hotel business}

The main problems of implementing information technologies in the hospitality and tourism industry include the high cost of these developments, the duration of staff training processes, and the adaptation of the built system of business processes of enterprises.

The reluctance of hotel management to introduce innovations is often associated with high risks of innovative projects in the hotel business. This is especially true for small hospitality businesses.

The problem is also the difficulty of attracting investment in the hotel business. Given that the payback period for the implementation of a hotel innovation project can be quite long, and the profit from them is not direct, but indirect, since they often do not give a direct effect, but only reduce the costs of the enterprise, such innovations are not of great interest to investors.

Another problem with the introduction of information technology in the hotel business is the lack of relevance of regulatory documents and legal barriers to the introduction of innovations. It happens that current innovations cannot be used in the enterprise, because they are not yet described in various regulations and rules, and what is not described is often forbidden to use.

In addition, the introduction of modern information technologies in the hospitality industry is complicated by the level of technical and technological complexity of implementation projects.

For example, the development of blockchain technologies in the tourism and hospitality industry is associated with two problems.

The first problem: integration with legacy systems.

Second problem: low transaction speed.

For example, a traditional reservation system can process 250,000 transactions per second. Lower speeds are simply unacceptable.

This is why we need platforms that can solve both of these problems. Such platforms can serve as a basis for third-party developers to program their standalone service with due consideration for outdated system integration and creating their own token. The maximum speed achieved on the platform must be at least 1 million transactions per second.

\section{Conclusions}

Information technologies are improving at a rapid pace, which directly affects the hotel business, changes the technology of its management, increases the efficiency of enterprises and provides unique opportunities to maintain competitiveness through the introduction of innovations in the activities of companies.

Assessing the state of the hotel market in the Russian Federation in terms of the development and use of modern information technologies, it is important to note that much depends on the hotel management. In the leading Russian hotels that are part of the global hotel chains, the work is fully automated, technological, and has its own computer and Internet services. Such hotels already have a successful experience in implementing modern information technologies.

It should be noted that the geography of such technology companies in the hotel business in Russia is very extensive. They are available in Moscow, St. Petersburg, Yekaterinburg, Sochi, Vladivostok, Novosibirsk and other major cities. The share of such hotels in the market is small in number, but there is a rule of "20 percent to 80 percent" that characterizes the specifics of the Russian hotel business, that is, 20 percent of active hotels provide 80 percent of customer needs. 
Customers of the hospitality industry already have a lot of experience in using mobile devices. These platforms have become one of the main channels of communication between hoteliers and their guests. Digital marketing is becoming a key channel of communication between the hotel and the network. At the same time, only the implementation of continuous data collection, processing, analysis and aggregation tasks will allow the management of hospitality enterprises to achieve one of their main goals - to better understand their customers and interact with them.

\section{References}

1. N. R. Saenko, V. V. Prokhorova, O. V. Ilyina, E. V. Ivanova, International Journal of Applied Business and Economic Research 15(11), 207-217 (2017).

2. O. V. Voronova, V. A. Khareva, T. S. Khnykina, International scientific journal (1), 19-25 (2019).

3. O. Kalinina, O. Valebnikova, Advances in Intelligent Systems and Computing 692, 1315-1322 (2018).

4. S. A. Chunikhin, E. A. Kuzmin, L. V. Pushkareva, Entrepreneurship and Sustainability Issues 6(4), 1663-1679 (2019). doi:10.9770/jesi.2019.6.4(8)

5. A. R. Bril, O. V. Kalinina, I. V. Ilin, Proceedings of the 30th International Business Information Management Association Conference, IBIMA 2017 , 2972-2980 (2017).

6. V. E. Stepanova, Modern Economy Success 6, 40-44 (2019).

7. E. A. Grudeva, E. V. Blanken, Global and Regional Research 1(1), 23-29 (2019).

8. V. Akberdina, L. Pushkareva, 4th International Conference on Social, Business, and Academic Leadership (ICSBAL 2019) (Atlantis Press 2019).

9. N. S. Morozova, M. M. Morozov, Bulletin of the Russian University. Series: The individual and society 1, 60-64 (2019).

10. T. S. Koval, M. A. Gritsay, Tourism industry: opportunities, priorities, challenges, and prospects 14(1), 294-302 (2019).

11. O. E. Pirogova, T. M. Smorchkova, Prospects of science 2(101), 77-81 (2018).

12. O. E. Pirogova, A. N. Rudakova, Science and business: way of development 3(81) $47-$ 52 (2018).

13. M. B. Yanenko, M. E. Yanenko, Problems of the modern economy 2(50), 227-230 (2014).

14. M. B. Yanenko, M. E. Yanenko, Proceedings of the Ural state University of Economics 2 (24), 45-51 (2009).

15. A. A. Evgrafov, O. Ilina, International scientific journal 1, 7-15 (2017) 